\title{
An Inverted Repeat Sequence of the IncFI Plasmid ColV2-K94 Increases Multimerization-mediated Plasmid Instability
}

\author{
By PETER C. WEBER AND SUNIL PALCHAUDHURI* \\ Wayne State University School of Medicine, Department of Immunology and Microbiology, \\ 540 E. Canfield Avenue, Detroit, Michigan 48201, USA
}

(Received 11 July 1985; revised 6 December 1985)

\begin{abstract}
A detailed physical map of the region of the IncFI plasmid ColV2-K94 containing the Rep1 replicon, a Tn903 transposon, and an inverted repeat structure $\left(\mathbf{X}_{1}\right)$ with unknown properties was prepared by cloning restriction fragments into $\mathrm{pBR} 325$. Inserts carrying the $1.2 \mathrm{~kb}$ repeated sequence of $\mathrm{X}_{1}$, but not the IS 903 sequence of Tn903, had a destabilizing effect on pBR325 and pBR322 plasmid maintenance. One of these derivatives, pWS139, was studied further and was shown to have elevated levels of multimeric DNA forms; this resulted in decreased copy number and plasmid instability, as multimerization reduces the effective number of randomly segregating plasmids per cell. A ColV2-K94 miniplasmid, which has a copy number much lower than that of ColE1-derived vectors, was also less stably inherited if it contained the $X_{1}$ structure. This destabilizing effect of the $\mathrm{X}_{1}$ repeat sequence was dependent on the RecA function, but not the $\mathrm{RecB}$ or the $\mathrm{RecC}$ functions of the host. These results suggest that the inverted repeat sequence of the $X_{1}$ structure serves as a 'hot-spot' for generalized recombination. Thus, when present in cis, this sequence can generate plasmid instability because plasmid molecules are readily converted into multimeric forms through enhanced recombination at this site.
\end{abstract}

\section{INTRODUCTION}

Bacterial plasmids have evolved a number of mechanisms for ensuring their stable inheritance in a population of dividing host cells. Large, stringently-controlled plasmids are maintained by efficient membrane-associated partitioning systems (Ogura \& Hiraga, 1983a; Austin \& Abeles, 1983), or by gene products which couple cell division to plasmid replication (Ogura \& Hiraga, 1983b). Small plasmids under relaxed replicational control tend to lack these elaborate partitioning mechanisms, as they can be stably maintained through their high copy numbers. Recently, Summers \& Sherratt (1984) presented strong evidence that the multicopy plasmid ColE 1 is randomly partitioned, and that multimerization of ColE1 derivative molecules in recombination-proficient strains leads to an increase in plasmid instability by reducing the number of segregating units per cell. These investigators found that instability through multimer formation is circumvented in the wild-type ColEl plasmid through $\operatorname{rec} A$-independent, sitespecific recombination at the $\operatorname{cer}(\mathrm{Col} E 1$ resolution) locus, which resolves multimeric plasmid forms into monomers. As the cer locus has been deleted in the construction of ColEl-derived cloning vectors, these plasmids show varying degrees of instability.

The ColE1-derived cloning vector pBR325, which was constructed from the widely-used pBR322 vector (Bolivar et al., 1977), was created to facilitate cloning of EcoRI restriction fragments through insertional inactivation of a chloramphenicol transacetylase gene (Bolivar, 1978; Prentki et al., 1981). Recently, we have completed a detailed restriction map of the $130 \mathrm{~kb}$ IncFI plasmid ColV2-K94 (Weber \& Palchaudhuri, 1985). We have used pBR325 to clone many of these restriction fragments in an attempt to study Repl, which is one of two replicons in the ColV2-K94 cointegrate plasmid, and is homologous to the RepA replicon of IncFII plasmids (Weber et al., 1984), and the three inverted repeat structures, $X_{1}, X_{2}$ and $X_{3}$, of ColV2-K94 (Mitra \& Palchaudhuri, 1984). 


\section{Table 1. E. coli strains and plasmids}

Strain or plasmid

Genotype and phenotype

Source or reference*

\section{E. coli \\ C600 \\ $\mathrm{C} 600\left(\operatorname{Rec} \mathrm{A}^{-}\right)$}

HB101

JC5519

C-2110

Plasmids

pWS 12

pWS15

pWS62

pWS63

pWS 109

pWS 139

pWS $139 \Delta 1$

pWS139 22

pWS 115

pWS 116

pWS502

pWS503

pWS202

pWS212

\author{
Hsd $\mathrm{M}^{-}$HsdR- thi-1 thr-1 leuB6 lacYl tonA2l supE44 \\ $\mathrm{RecA}^{-} \mathrm{HsdM}^{-} \mathrm{HsdR}^{-}$thi-I thr-1 leuB6 lacYl tonA21 \\ supE44 \\ recAl3 hsdS20 ara-14 proA2 lac Y1 galK2 rpsL20 xyl-5 \\ mtl-1 supE44 \\ recB21 recC22 thr-1 leuB6 proA2 hisG4 argE3 thi-1 \\ ara-14 lacYl galK2 xyl-5 mtl-l rpsL31 ts.r-33 supE44 \\ polAl $\mathrm{His}^{-} \mathrm{Rha}^{-}$
}

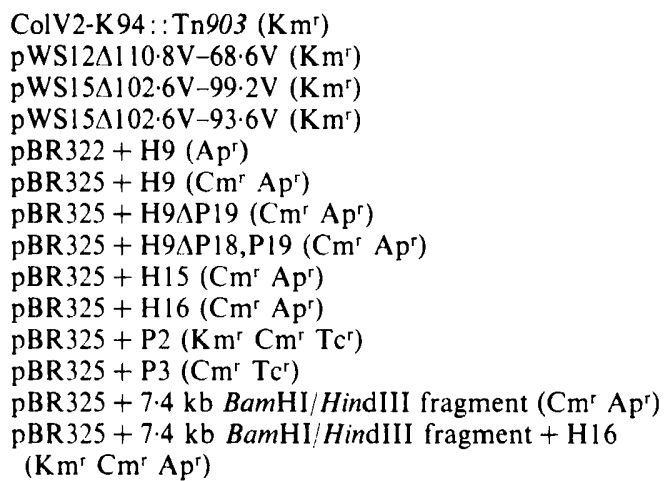

S. N. Cohen

This laboratory

H. W. Boyer

B. Bachmann

D. R. Helinski

Mitra \& Palchaudhuri (1984)

Weber et al. (1984)

This work

This work

This work

This work

This work

This work

This work

This work

This work

This work

This work

This work

* Addresses: B. Bachmann, E. coli Genetic Stock Center, Yale University, Conn., USA, H. W. Boyer, University of California at San Francisco, Calif., USA; S. N. Cohen, Stanford University School of Medicine, Stanford, Calif., USA; D. R. Helinski, University of California, San Diego, Calif., USA.

In this work, we provide evidence that a cloned inverted repeat sequence of the ColV2-K94 stem-loop structure $\mathrm{X}_{1}(1.2 \mathrm{~kb}$ stem and $1.4 \mathrm{~kb}$ loop $)$ destabilizes pBR325 as well as ColV2-K94 miniplasmids by increasing plasmid multimerization. As this phenomenon is rec $A$-dependent, the $\mathrm{X}_{1}$ repeat sequence appears to function as a 'hot-spot' for generalized recombination in generating elevated levels of multimeric plasmid forms. Since it converts monomeric plasmid molecules into multimers, this sequence behaves in a manner which is exactly opposite that of the cer locus carried on the wild-type ColE1 plasmid.

\section{METHODS}

Strains and media. The strains of Escherichia coli used are listed in Table 1. The media used included LB medium and $\mathrm{M}-9$ medium. Antibiotics were added to give the following final concentrations: kanamycin at $70 \mu \mathrm{g} \mathrm{ml}^{-1}$, chloramphenicol at $50 \mu \mathrm{g} \mathrm{ml}^{-1}$, ampicillin at $50 \mu \mathrm{g} \mathrm{ml}^{-1}$ and tetracycline at $20 \mu \mathrm{g} \mathrm{m} l^{-1}$.

Recombinant plasmids and cloning procedures. The construction of the ColV2-K94 deletion derivative pWS15 (ColV2-K94 : : Tn903 $1110.8 \mathrm{~V}-68.6 \mathrm{~V}$ ) was described by Weber et al. (1984). Restriction fragments of pWS15 generated with PstI, HindIII and BamHI/HindIII were cloned into pBR325 according to the procedures of BRL. Self-replicating miniplasmids of pWSI 5 were constructed by digesting plasmid DNA with PstI, ligating with T4 DNA ligase and transforming into $E$. coli $\mathrm{C} 600$ with selection for kanamycin resistance. All recombinant plasmids generated in this work are listed in Table 1 and illustrated in Fig. 1. Plasmid DNA was isolated on caesium chloride/ethidium bromide gradients (Palchaudhuri et al., 1976) or by a rapid alkaline extraction procedure (Birnboim \& Doly, 1979).

Plasmid stability testing. Stability of pBR 325 clones was measured by growing an overnight culture of each strain with chloramphenicol selection, diluting to $10^{-7}$ in M-9 medium without antibiotic, and growing to stationary phase. This process of dilution and incubation was repeated three more times. Each cycle was found to consist of 20 generations, and the loss of chloramphenicol marker was determined after each cycle.

Stability of ColV2-K94 miniplasmids was measured over a much shorter time, due to their greater instability. An overnight culture of each strain was grown in kanamycin selection, diluted to $10^{-7}$ in LB medium without antibiotic, and grown to stationary phase. During this growth period, samples were diluted and plated at $0,4,7$, and $10 \mathrm{~h}$. These plates were used to determine the number of elapsed generations as well as the loss of the kanamycin resistance marker. 
(a)
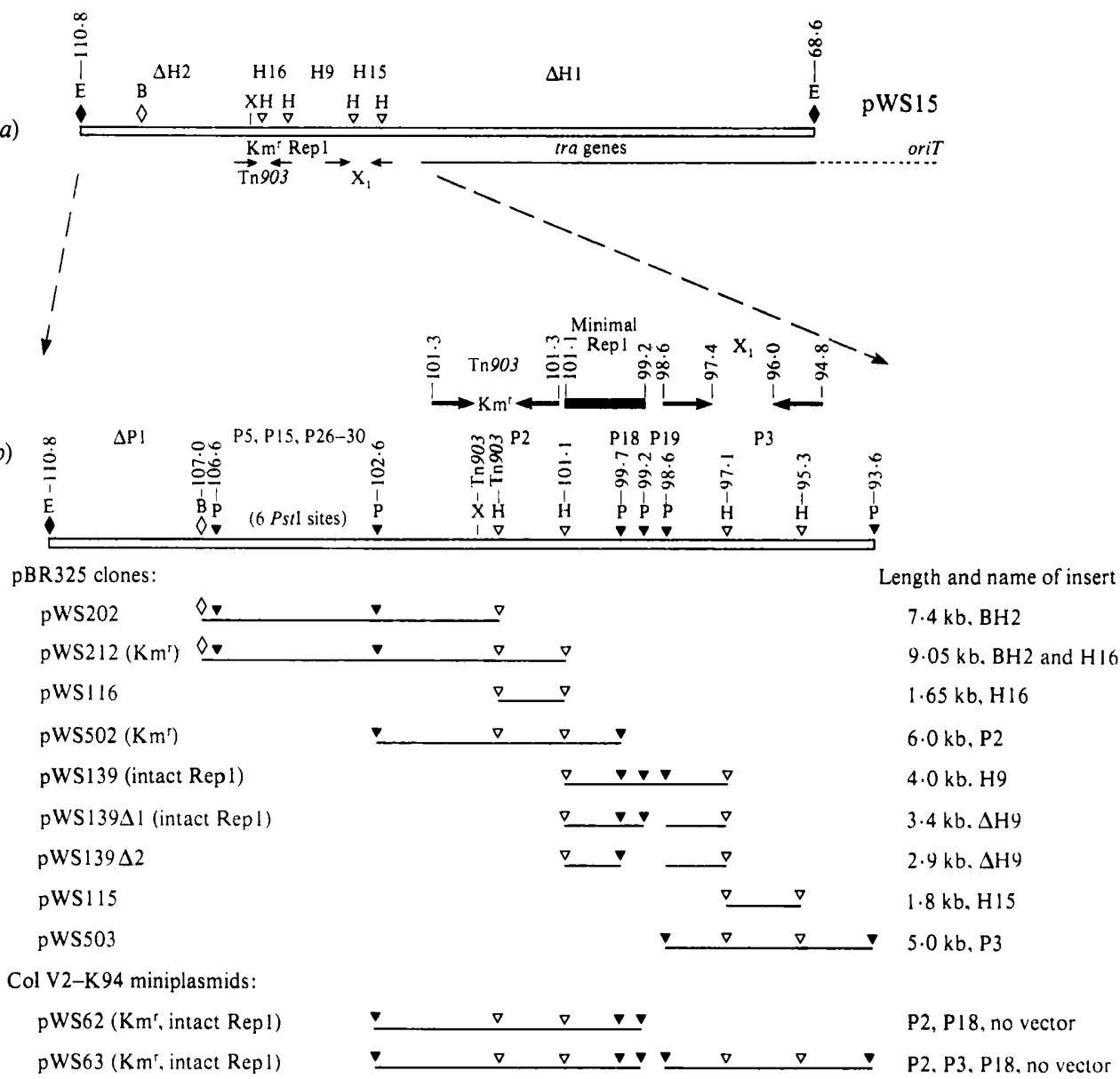

Fig. 1. (a) Physical and genetic map of pWS15 (Weber \& Palchaudhuri, 1985), showing EcoRI (E), BamHI (B), Xhol (X), and HindIII (H) restriction sites; inverted repeats (arrows) of Tn903 and the $\mathrm{X}_{1}$ structure; and the location of the Repl replicon and distal portion of the transfer (tra) operon. (b) Fine structure map of the 'non-tra' region of pWS15. PstI (P) restriction sites were mapped by Pst I/HindIII double digests of the pBR325 clones shown. Tn903 was cloned intact on two inserts which conferred kanamycin resistance in pWS212 and pWS502. Repl was functional in pWS139 and pWS139 1 , based on the ability of these clones to rescue pBR325 replication in the PolA- host C-2110. The two miniplasmids shown contained both Tn903 and Repl and were self-replicating (i.e. lacked the pBR325 vector). The coordinate system is that of Sharp et al. (1973).

\section{RESULTS}

Cloning and mapping the RepI replicon, Tn903 transposon and inverted repeat structure $X_{1}$ of ColV2-K94. The construction of pWS15, the largest EcoRI fragment of the ColV2-K94:: Tn903 derivative pWS12 (Mitra \& Palchaudhuri, 1984), was described by Weber et al. (1984). This deletion derivative extends from $68.6 \mathrm{~V}$ to $110.8 \mathrm{~V}$ and includes the Repl replicon, Tn903 transposon, inverted repeat structure $\mathrm{X}_{1}$ and much of the distal portion of the ColV2-K94 tra operon (Fig. 1). The unique EcoRI, BamHI and XhoI sites, and one of four HindIII sites, have already been mapped on pWS15 (Weber \& Palchaudhuri, 1985). The remaining three HindIII sites (which generate the $\mathrm{H} 9, \mathrm{H} 15$ and $\mathrm{H} 16$ HindIII fragments) as well as 12 Pst I sites of the 'non-tra' region of pWS15 were mapped in this work through double digest analysis of restriction fragments cloned in pBR325 (Fig. 1).

Due to the unique HindIII and XhoI sites found in Tn903 (Grindley \& Joyce, 1980), the insertion and orientation of this transposon was accurately determined (Weber \& Palchaudhuri, 
Table 2. Stability of cloned restriction fragments and miniplasmids of ColV2-K94

\begin{tabular}{|c|c|c|c|}
\hline $\begin{array}{l}\text { Host } \\
\text { strain }\end{array}$ & Plasmid & $\begin{array}{l}\text { Frequency of loss } \\
(\% \text { plasmidless cells } \\
\text { per generation })\end{array}$ & $\begin{array}{l}\text { Increase in } \\
\text { instability } \\
\text { (fold) }\end{array}$ \\
\hline \multicolumn{4}{|c|}{$p B R 325$ and $p B R 322$ clones } \\
\hline $\mathrm{C} 600 \mathrm{Rec}^{+}$ & $\begin{array}{l}\text { pBR325 } \\
\text { pWS } 116 \\
\text { pWS212 } \\
\text { pWS } 503 \\
\text { pWS } 115 \\
\text { pWS } 139 \\
\text { pWS } 139 \Lambda 1 \\
\text { pWS } 139 \Lambda 2\end{array}$ & $\begin{array}{l}0.08 \\
0.13 \\
0 \cdot 18 \\
0.48 \\
0.53 \\
0.78 \\
0.62 \\
0.84\end{array}$ & $\begin{array}{r}- \\
1 \cdot 6 \\
2 \cdot 3 \\
6.0 \\
6.6 \\
9.8 \\
7.8 \\
10.5\end{array}$ \\
\hline C600 RecA- & $\begin{array}{l}\text { pBR325 } \\
\text { pWS139 monomer }\end{array}$ & $\begin{array}{l}<0.01 \\
<0.01\end{array}$ & $\overline{0}$ \\
\hline $\mathrm{HB} 101 \mathrm{RecA}^{-}$ & $\begin{array}{l}\text { pBR325 } \\
\text { pWS139 monomer } \\
\text { pWS139 dimer }\end{array}$ & $\begin{array}{l}0.01 \\
0.03 \\
0 \cdot 34\end{array}$ & $\begin{array}{r}- \\
3 \cdot 0 \\
34 \cdot 0\end{array}$ \\
\hline JC5519 RecBC- & $\begin{array}{l}\text { pBR325 } \\
\text { pWS139 }\end{array}$ & $\begin{array}{l}0.09 \\
0.56\end{array}$ & - \\
\hline $\mathrm{C} 600 \mathrm{Rec}^{+}$ & $\begin{array}{l}\text { pBR322 } \\
\text { pWS } 109\end{array}$ & $\begin{array}{l}0.01 \\
0.58\end{array}$ & $\overline{58 \cdot 0}$ \\
\hline \multicolumn{4}{|c|}{ ColV2-K94 miniplasmids } \\
\hline $\mathrm{C} 600 \mathrm{Rec}^{+}$ & $\begin{array}{l}\text { pWS62 } \\
\text { pWS63 }\end{array}$ & $\begin{array}{l}2 \cdot 4 \\
4 \cdot 6\end{array}$ & $\overline{1.9}$ \\
\hline
\end{tabular}

1985); Tn903 was cloned intact in this work in the pBR325 derivatives pWS212 and pWS502 (Fig. 1). Since electron microscopy of the pWS15 homoduplex molecule (not shown) revealed that the stem-loop structures Tn903 and $X_{1}$ were separated by a distance of $2.7 \mathrm{~kb}$, the $X_{1}$ inverted repeat structure could also be positioned on the pWS15 restriction map. One of the $X_{1}$ repeat sequences was located on pWS139 and its deletion derivatives, and the entire structure was cloned on pWS503. The Repl replicon, located between $X_{1}$ and $T n 903$, was cloned in pWS139 and pWS13941, as these plasmids could replicate in the PolA ${ }^{-}$strain C-2110.

Implication of the cloned $X_{1}$ repeat in the instability of $p B R 325$ clones. It was observed during the rapid isolation (Birnboim \& Doly, 1979) screening of pBR325 clones of pWS15 that some recombinant plasmid restriction patterns were markedly fainter on ethidium bromide-stained agarose gels than others, suggesting a decrease in the stable inheritance of these clones due to copy number reduction. All of these clones (pWS139 and its derivatives, and pWS503) shared the $1.55 \mathrm{~kb}$ Pst $\mathrm{I} /$ Hind III fragment of $\mathrm{pWS15}$, which contains a complete $1.2 \mathrm{~kb}$ repeat of the $\mathrm{X}_{1}$ stem-loop structure (Fig. 1). Unfortunately, this restriction fragment could not be cloned directly into pBR325 as it would result in the loss of all three selection markers (ampicillin, tetracycline and chloramphenicol resistance) of this vector.

As ColE1 is randomly partitioned (Summers \& Sherratt, 1984), if the copy numbers of these pBR325 clones were indeed reduced, the stability of these plasmids would be affected as well. To examine this effect, the stability of the pBR325 clones in the absence of antibiotic selection was measured over a period of 80 generations. The plasmids chosen for study were pBR325 without a cloned insert; pWS139, pWS139 $\Delta 1$ and pWS139 22, which contain the first $\mathrm{X}_{1}$ repeat on the

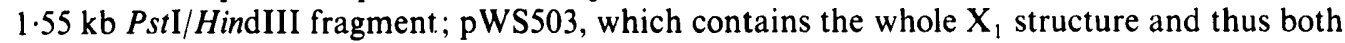
$\mathrm{X}_{1}$ repeats; $\mathrm{pWS} 115$, which contains $0.75 \mathrm{~kb}$ of the second $\mathrm{X}_{1}$ repeat; $\mathrm{pWS} 116$, which contains a complete IS 903 sequence of $\operatorname{Tn} 903$; and pWS212, which contains the whole $\operatorname{Tn} 903$ transposon.

A comparison of the frequencies of loss of these plasmids (summarized in Table 2) indicated that one or both copies of the IS 903 repeat of Tn903 had no effect on pBR325 stability when cloned, while the presence of both or one or even a portion of one of the $X_{1}$ repeats on the pBR325 vector increased plasmid instability six- to tenfold. This apparent effect of the $X_{1}$ repeat on pBR325 stability was cis- and not trans-acting, as the stability of the vector was unaffected by 
A

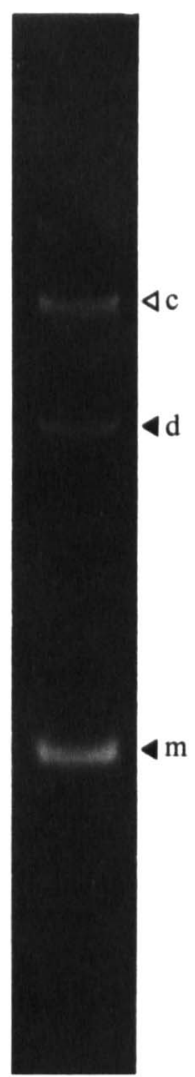

B

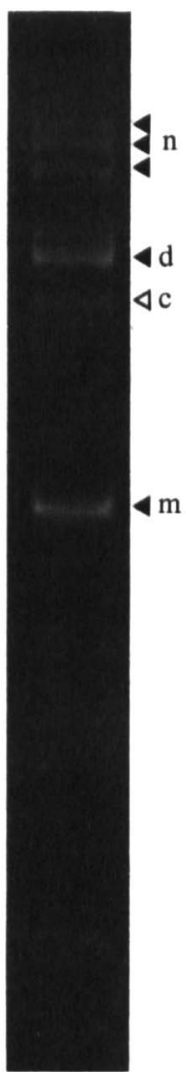

$\mathrm{C}$

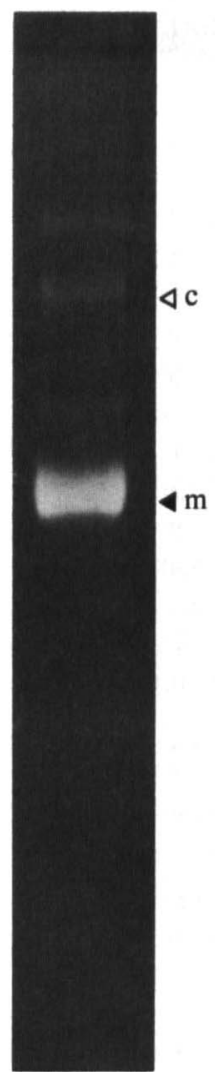

D

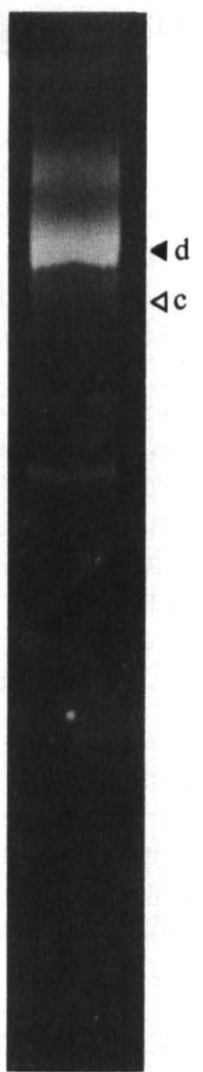

E

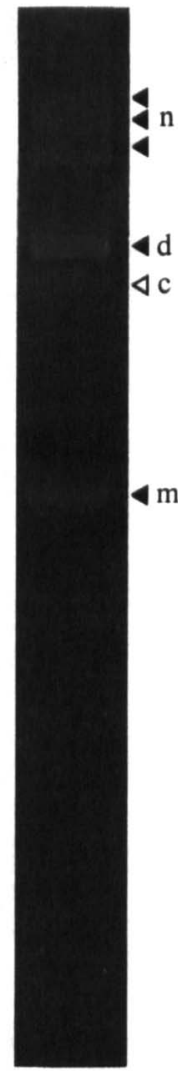

Fig. 2. Rapid alkaline (Birnboim \& Doly, 1979) isolations of pBR325 and pWS139, a pBR325 derivative carrying an $X_{1}$ repeat sequence. Lane $A, C 600 \mathrm{Rec}^{+}$(pBR325); lane B, C600 Rec ${ }^{+}$ (pWS139); lane C, HB101 RecA- (pWS139 monomer); lane D, HB101 RecA- (pWS139 dimer); lane E, JC5519 RecBC- (pWSI39). Monomeric (m), dimeric (d) and multimeric (n) plasmid forms and chromosomal DNA (c) are indicated. Note the elevated levels of dimers and multimers of pWSI 39 in C600 Rec ${ }^{+}$and JC5519.

a co-resident pWS15 plasmid (data not shown), and was independent of the vector used, as pWS109, the pBR322 analogue of pWS139, also showed a pronounced instability in C600 (Table 2).

Recent reports (Kasner et al., 1985) have suggested that the stability of ColEl vectors decreases as the size of their cloned inserts increases. This does not appear to be the case in the pWS 15 clones, as the $X_{1}$ repeat inserts range in size from $1.8 \mathrm{~kb}$ (pWS115) to $5.0 \mathrm{~kb}$ (pWS503), and all confer instability on their vector. Also, the plasmid carrying the largest cloned fragment, pWS212 ( $9.05 \mathrm{~kb}$ insert), appears to be relatively stable when compared to pBR325 without an insert.

The $X_{1}$ repeat increases $p B R 325$ instability through RecA-dependent multimerization. Summers \& Sherratt (1984) demonstrated that ColEl vector instability was due to an increase in multimeric forms of these plasmids. To see if increased multimerization was responsible for the instability of the $X_{1}$ repeat clones, rapid alkaline isolations (Birnboim \& Doly, 1979) were done on these plasmids. All of the clones carrying the $\mathrm{X}_{1}$ repeat showed a greater degree of multimerization than pBR325 or other pWS15 clones. The isolate of one such plasmid, pWS139, is compared with pBR325 in Fig. 2, demonstrating the abundance of dimeric and multimeric forms in the 
plasmid population of $\mathrm{pBR} 325$ which carries an $\mathrm{X}_{1}$ repeat sequence; $\mathrm{pBR} 325$ without an insert exists in predominantly monomeric form.

As these experiments had so far been done in a recombination-proficient strain, $\mathrm{C} 600$, the effects of the $\mathrm{X}_{1}$ repeat on pBR325 maintenance were then studied in recombination-deficient strains. pWS139, a representative $\mathrm{X}_{1}$ clone, was isolated from $\mathrm{C} 600$ and transformed into an isogenic C600 Rec $\mathrm{A}^{-}$strain, the RecA- strain HB101 and the $\mathrm{RecB}^{-} \mathrm{RecC}^{-}$strain JC5519. This pBR325 derivative was stably inherited (Table 2) and exhibited reduced multimerization (Fig. 2 ) in the two RecA- strains but not in the $\operatorname{RecBC}^{-}$strain, so that instability due to $\mathrm{X}_{1}$-mediated multimerization was a RecA-dependent but RecBC-independent process. Interestingly, transformants in the RecA- strains carried pWS139 in exclusively either a monomeric state or a dimeric state (Fig. 2). The latter was presumably due to the transformation of dimeric DNA molecules (prevalent in the $\mathrm{C} 600$ host) into a strain in which these plasmids cannot be resolved into monomeric forms due to the loss of RecA recombination functions.

As would be expected, the pWS139 monomer was quite stable in the RecA- strain HB101, while the pWS139 dimer was relatively unstable: the monomeric clone was only three times as unstable as pBR325 without an insert, compared to 34 times the instability for the dimeric clone (Table 2). These results confirm that an increase in dimers and other multimeric forms in a pBR325 plasmid population, as mediated by enhanced RecA-dependent recombination occurring at a cloned $X_{1}$ sequence, would serve to reduce stable maintenance.

Effect of the $X_{1}$ repeat sequence on ColV2-K94 stability. ColV2-K94 is inherited quite stably in a RecA $\mathrm{A}^{-}$background (frequency of loss $<0.05 \%$ per generation), but not in a $\operatorname{Rec} \mathrm{A}^{+}$background (frequency of loss $=2-5 \%$ per generation; unpublished observations). This notable difference suggests that RecA-dependent multimerization may also have marked effects on ColV2-K94 stability. To test whether the $X_{1}$ repeat had any role in this instability, ColV2-K94 miniplasmids were constructed in vitro using PstI; these derivatives, pWS63 and pWS62, consisted purely of Tn903 (used as a selection marker) and the minimal Repl, with and without the $\mathrm{X}_{1}$ structure, respectively (Fig. 1).

The stability of pWS62 and pWS63 was compared over a period of 20 generations in the recombination-proficient strain $\mathrm{C} 600$. The presence of the $\mathrm{X}_{1}$ structure on the ColV2-K94 miniplasmid pWS63 caused it to have a twofold increase in instability, compared with the pWS62 miniplasmid (Table 2). Thus, even in ColV2-K94, a plasmid with a low copy number (about two copies per chromosome; Mitra \& Palchaudhuri, 1984), the $\mathrm{X}_{1}$ repeat sequence can enhance instability in a recombination-proficient strain.

\section{DISCUSSION}

The ColE1-derived vector pBR325 was used to clone restriction fragments of ColV2-K94 carrying the Repl replicon, $T n 903$ transposon and $X_{1}$ inverted repeat structure. In the process, a detailed physical map of the area of ColV2-K94 containing these functions $(93.6 \mathrm{~V}-107.0 \mathrm{~V})$ was also prepared (Fig. 1). Cloning these regions onto small restriction fragments has enabled us to study the functioning of Repl, an IncFII-like replicon on an IncFI plasmid (Weber et al., 1984), and the inverted repeat structure $\mathbf{X}_{1}$.

The evidence presented here suggests that the inverted repeat sequence of the $X_{1}$ structure is a 'hot-spot' for generalized, RecA-dependent recombination. When both (pWS503), one (pWS139 and its derivatives), or even part of one ( $\mathrm{pWS115)}$ of the $\mathrm{X}_{1}$ repeat sequences were cloned into pBR325, the resulting plasmids had increased instability due to elevated multimerization and reduced copy number of the vector molecules. A similar effect was also seen in a derivative of the stringently-controlled plasmid ColV2-K94 which contained the $\mathrm{X}_{1}$ structure. This phenomenon was not observed in pBR325 derivatives containing one (pWS116) or two (pWS212) copies of the insertion sequence IS 903 of the Tn 903 transposon. The instability of the pBR325 clones was not due to insert molecular mass, as demonstrated by the assorted sizes of restriction fragments carrying the $\mathrm{X}_{1}$ repeat which could cause instability, nor was it dependent on the RecB or RecC functions of the host.

Now that the $X_{1}$ inverted repeat structure has been cloned onto small restriction fragments, it 
will be interesting to study its characteristics, as $X_{1}$, whose stem-loop structure was reported long ago (Sharp et al., 1973), may be a transposon with unknown phenotypic properties. This is suggested by the observation that ColV2-K94 can readily alter itself through rearrangement of its three inverted repeat structures (Davies et al., 1982; Mitra \& Palchaudhuri, 1984). The ability of an IS element to serve as a hot-spot for recombination is common in bacterial systems. RecAdependent recombination at homologous IS sequences is commonly used in the integration of plasmids into host genomes (Davidson et al., 1975), and the transitioning and amplification of $\mathrm{R}$ plasmid DNA is a RecA-dependent process known to occur at insertion elements such as ISI (Rownd, 1982). It therefore seems feasible that an IS sequence, when cloned on a multicopy plasmid, could increase the number of unstable multimeric forms in the plasmid pool by simple homologous recombination between molecules.

\section{REFERENCES}

Austin, A. \& ABELES, A. (1983). The partition of unitcopy miniplasmids to daughter cells. II. The partition region of miniplasmid $\mathrm{Pl}$ encodes an essential protein and a centromere-like site at which it acts. Journal of Molecular Biology 169, 373-387.

Birnboim, H. C. \& Doly, J. (1979). A rapid alkaline extraction procedure for screening recombinant DNA. Nucleic Acids Research 7, 1513-1523.

Bolivar, F. (1978). Construction and characterization of new cloning vehicles. III. Derivatives of plasmid pBR322 carrying unique EcoRI sites for selection of EcoRI-generated recombinant molecules. Gene 4, 121-136.

Bolivar, F., Rodriguez, R. L., Green, P. J., Betlach, M. C., Heyneker, H. L., Boyer, H. W., Crosa, J. H. \& Falkow, S. (1977). Construction and characterization of new cloning vehicles. II. A multipurpose cloning system. Gene 2, 95-113.

Davies, D. L., BINNS, M. M. \& HARDY, K. G. (1982). Sequence rearrangements in the plasmid ColV,IK94. Plasmid 8, 55-72.

Davidson, N., Deonier, R. C., Hu, S. \& OHtsubo, E. (1975). Electron microscope heteroduplex studies of sequence relations among plasmids of Escherichia coli. X. Deoxyribonucleic acid sequence organization of $F$ and of F-primes, and the sequences involved in $\mathrm{Hfr}$ formation. In Microbiology - 1974, pp. 56-65. Edited by D. Schlessinger. Washington, DC: American Society for Microbiology.

Grindley, N. D. F. \& JOYCE, C. M. (1980). Analysis of the structure and function of the kanamycinresistance transposon Tn903. Cold Spring Harbor Symposia on Quantitative Biology 45, 125-133.

KASNER, J. P., Womble, D. D. \& Rownd, R. H. (1985). Relationship between plasmid copy number and molecular size of the plasmids ColEl and NRl (abstract). In Plasmids in Bacteria. p. 861. Edited by D. R. Helinski, S. N. Cohen, D. B. Clewell, D. A. Jackson \& A. Hollaender. New York: Plenum Press.

Mitra, G. \& Palchaudhuri, S. (1984). Genetic structure and stability of a copy number mutant of
IncFI group plasmid ColV2-K94 in Escherichia coli K12. Molecular and General Genetics 193, 349-357.

Ogura, T. \& Hiraga, S. (1983a). Partition mechanism of $F$ plasmid: two plasmid gene-encoded products and a cis-acting region are involved in partition. Cell 32, 351-360.

Ogura, T. \& Hiraga, S. (1983b). Mini-F plasmid genes that couple host division to plasmid proliferation. Proceedings of the National Academy of Sciences of the United States of America 80, 4784-4788.

Palchaudhuri, S., Maas, W. K. \& Ohtsubo, E. (1976). Fusion of two F-prime factors in Escherichia coli studied by electron microscope heteroduplex analysis. Molecular and General Genetics 146, 215 231.

PrentKi, P., KarCh, F., IIDA, S. \& Meyer, J. (1981). The plasmid cloning vector pBR 325 contains a 482 base-pair-long inverted duplication. Gene 14, 289299.

RowND, R. H. (1982). R plasmid drug resistance gene amplification in bacteria. In Gene Amplification, pp. 273-279. Edited by R. T. Schimke. Cold Spring Harbor, New York: Cold Spring Harbor Laboratory.

Sharp, P. A., Cohen, S. N. \& Davidson, N. (1973). Electron microscope heteroduplex studies of sequence relations among plasmids of Escherichia coli. II. Structure of drug resistance (R) factors and $F$ factors. Journal of Molecular Biology 75, 235-255.

Summers, D. K. \& SherRatT, D. J. (1984). Multimerization of high copy number plasmids causes instability: ColE1 encodes a determinant essential for plasmid monomerization and stability. Cell 36, 1097-1103.

Weber, P. C. \& Palchaudhuri, S. (1985). A physical and genetic map of the IncFI plasmid ColV2-K94. Plasmid 13, 215-218.

Weber, P. C., Mitra, G. \& Palchaudhuri, S. (1984). Second replicon in ColV2-K94 mediates the stable coexistence of two incompatible plasmids. Journal of Bacteriology 162, 245-250. 